\title{
New fire control system design for fire fighting and rescue equipment
}

\author{
Jianguo $\mathrm{LUO}^{1, \mathrm{a}}$, Zehao BU ${ }^{2, \mathrm{~b}}$ \\ ${ }^{1}$ Department of Mechanical and Electrical Engineering, North China Institute of Science and \\ Technology, East Suburb of Beijing, 101601, China \\ ${ }^{2}$ Department of Graduate School, North China Institute of Science and Technology, East Suburb of \\ Beijing, 101601, China

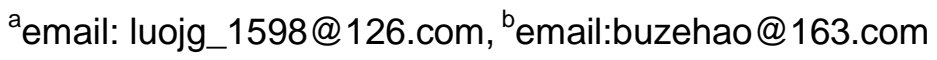

Keywords: System Design; High-rise Fire; PLC; Control System

\begin{abstract}
In this article we put forward a new embedded scalable fire rescue equipment which is based on system thinking, and combined with fire refuge floors of high-rise buildings, matching with special firefighting media transmission and fire control system. Thereby supporting the design of a PLC-based fire control system, through the design of electrical equipment main circuit, control circuit, PLC control circuit, when a fire alarm system start, ground control room start the firefighting and rescue equipment in the fire spot and make it extend outside the building, the fire equipment installed with monitoring and information transfer systems, firefighting spray gun remote control system, realizing full coverage, high efficiency, remote control firefighting outside the building. And debug PLC programs to check the rationality and operational of the system, proved to achieve the desired objectives.
\end{abstract}

\section{Introduction}

With the rapid economic growth, high-rise buildings are the human's wisdom, but the fires of high-rise buildings have brought great damage to human [1]. Because of the limited height of the existing firefighting system, people can only rely more on indoor fixed fire extinguishing systems, if the indoor water used for fire is insufficient and pressure is low or even signal is interfered then how to put out fire is a tough problem [2]. And most of the fire-extinguishing system in buildings is a combination of detector and sprinkler system; fire extinguishing is not optimistic [3]. After analyzing the performance of various firefighting mechanisms and practicability of automatic fire extinguishing system, impact factors, efficiency and capability [4], we proposed a PLC-based embedded scalable fire extinguishing and rescue equipment control system. According to China's fire safety requirements, high-rise buildings exceeding 100m every 15 -storey should build a refuge layer [5] in which installed with the embedded scalable fire rescue and extinguishing equipment. This fire control system enhanced the flexibility and efficiency of the rescue equipment, when fire occurs the central control system using ground fire extinguishing systems, which is more effective than intelligent remote fire artillery [6], providing a new approach for high-rise building fire extinguishing rescue.

\section{Embedded scalable extinguishing system}

Embedded scalable extinguishing equipment (Fig.1) consists of three parts: telescopic rails, fire extinguishing system, ground remote central control system. Telescopic rails mounted horizontally on a high-rise building refuge layer matching with scalable extinguishing media transport pipeline, when fire occurred telescopic rails automatically or manually extend from refuge layer, scalable rail rotation is controlled by a motor, then the multi-stage cylinder stretch out. Fire extinguishing system is installed in the forefront of multi-stage telescopic cylinder, constituted by the fire control room, fire gun, fire monitoring device, gun control system; fire monitoring transmission system, the main task is to send real-time image of fire to ground central control room screen, precisely control extinguishing medium inject into the building. Remote central control system consists of ground 
fire live image display system, gun remote control system, extinguishing medium transport control system. Ground remote central control system controls the entire extinguishing process and the operation of other components.

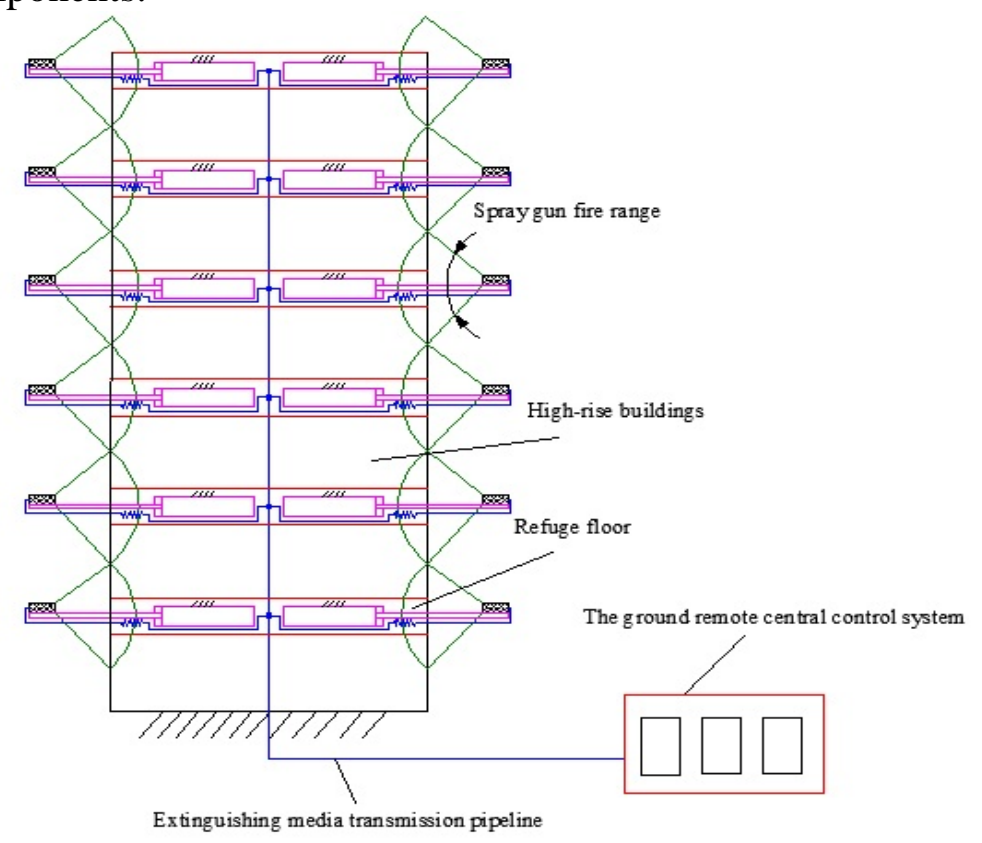

Figure 1: Working schematic diagram

\section{Main circuit design}

Main circuit in fire extinguishing system of embedded retractable fire rescue equipment mainly consist of two pumps (one is for spare), booster pumps, two electric motors control rail rotating out from refuge floor, mainly provide firefighting medium for fire extinguishing system from the ground, a spare pump to make the transmission of extinguishing medium more reliable, a booster pump between two refuge floors to make up for the pressure loss.

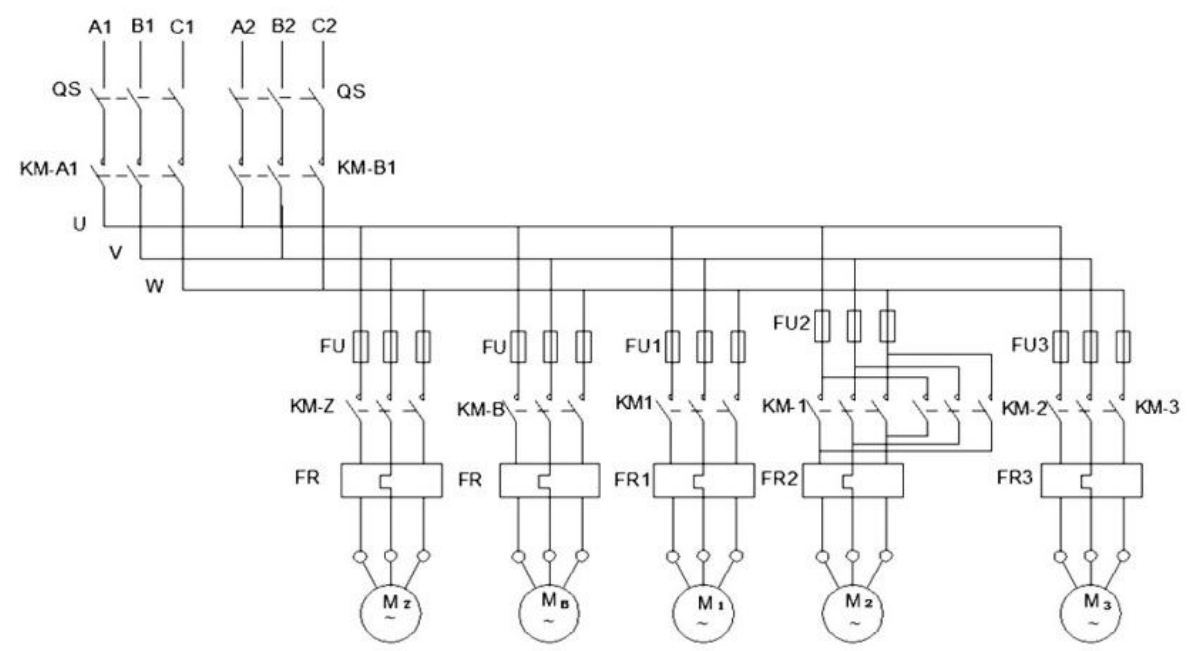

Figure 2: The main circuit diagram

\section{Control circuit design}

Control circuit consists of push button switches, signal relays, exchanges and contacts, trip switches and other devices, automatically or manually control retractable telescopic rails, main pump, booster pump to achieve the functions of system. 


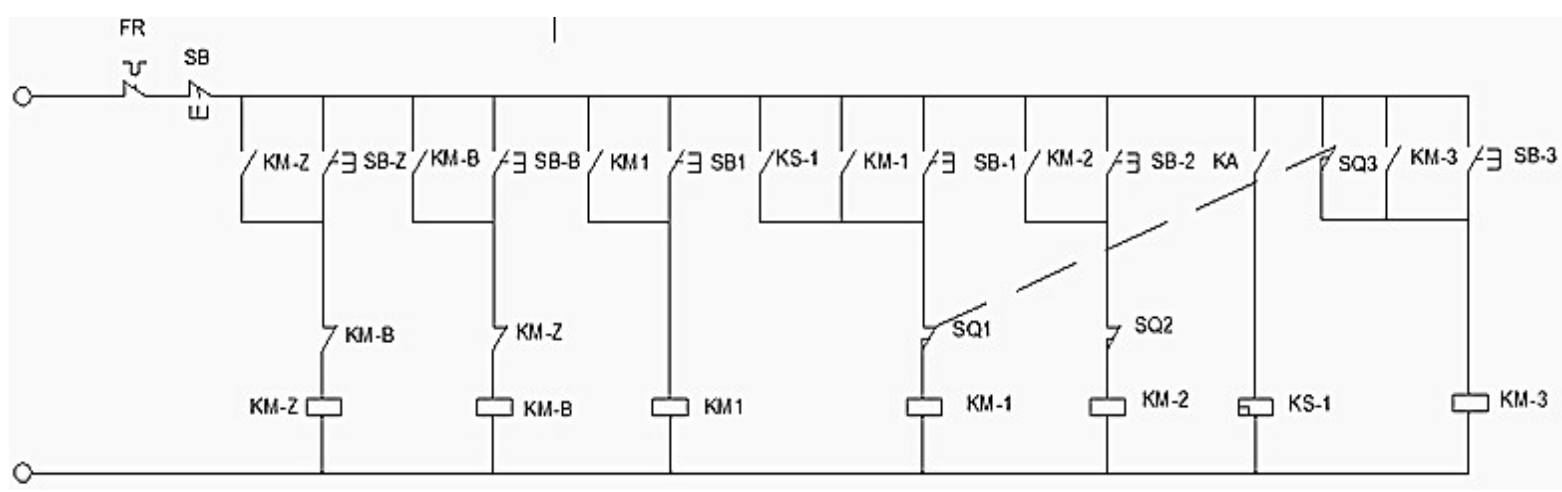

Figure 3: Control Circuit Diagram

\section{Auxiliary circuit design}

In order to ensure these devices running all the time, the system design requires there must be two-way power supply. In order to provide reliable power supply of high-rise building fire, dual power switching power supply is designed, this is the main line and backup line road.
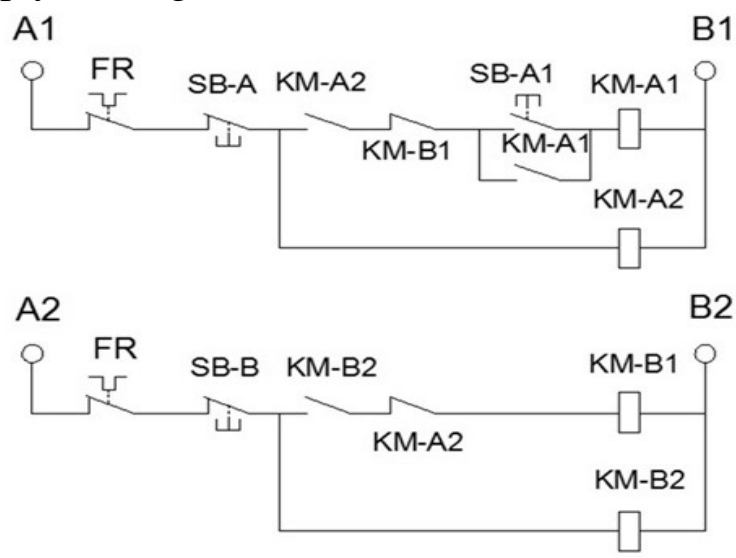

Figure 4: Dual power supply switching control circuit diagram

\section{Control Process}

When found the building is on fire, the system shall be alarmed, the contactor KM-1 was electric, control telescopic rails rotates out of refuge floors, when reached a certain angle, touch the limit switch SQ1, make the telescopic rails rotation stopped. In case fire alarm monitoring system or warning system accidentally damaged, it can be manually controlled by ground control room, so it can also extend the telescopic rails from the refuge. Fire fighting gun is mainly controlled by two electric motors, thereby aligning the ignition point. Each refuge floors' main circuit and telescopic rails branches are equipped with an electric valve, through the ignition point effectively open the valve, the electric valve is controlled via wireless GPRS, computer control the open state, also central control room can open state through wiring valve, preparing for the subsequent fire extinguishing media saving, and media transmission. Pressing the button switch SB-Z starts the main pump, start extinguishing medium convey to the gun, spray into the building. In order to avoid accidental fire pump clogging or damaging, installed another spare pump. Press the button SB-B, the main contact is closed, the standby pump is start. When the fire is put out, press the button switch SB-2 telescopic rails retracted and rotated back into the refuge floor, firefighting is finished. Since fire may be accompanied with power outage, this system design also enables backup power to ensure the entire system can continue to work. The following is a control flowchart: 


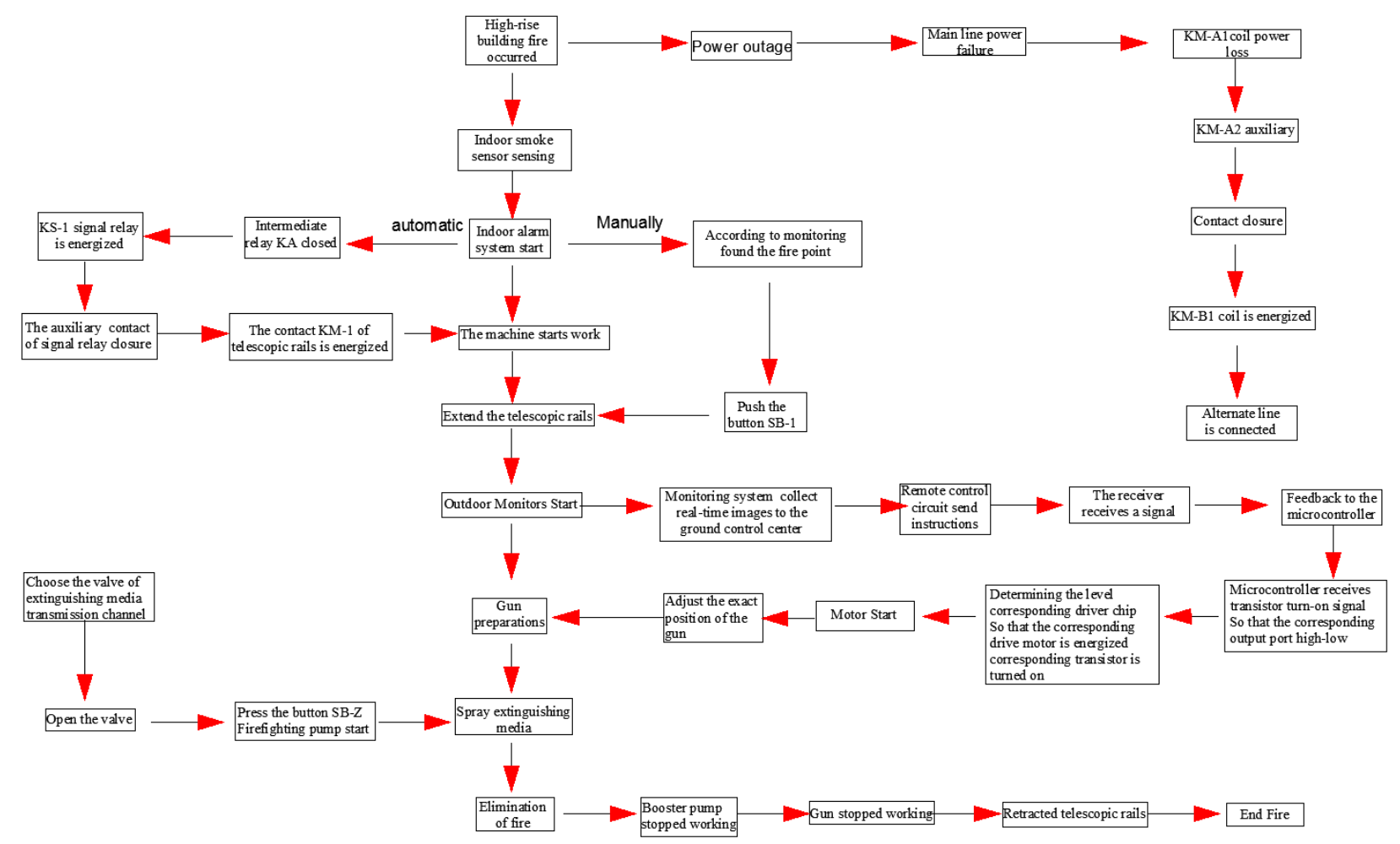

Figure 5: Fire control flow chart

\section{PLC control design}

Using Siemens S7-200 PLC, Input section: Button SB-Z, SB-B, SB1 respectively control the main pump, the standby pump, booster pump start, SB-A1, SB-A, SB-B are respectively double power automatic switch main line buttons, broken dual power automatic standby line switch button, disconnect the two power supply automatically switches the main line button, SB-1, SB-2 is extendable and retractable telescopic rails button, SB is the total stop button.

Output section: KM-A1, KM-B1 were respectively the contactor of dual power automatic switch of the main line and the standby line, KM-A2, KM-B2 are double power automatic switch main line and standby line interlock contacts, two loops prevent cross conduction, KM-Z, KM-B, KM1 were main and backup pump, booster pump contactors, KM-1, KM-2, respectively controlling telescopic rails rotary contactor, KS-1 signal relay contact when the relay is closed, the signal relay is energized, so that the rail was electric extend from refuge floor.

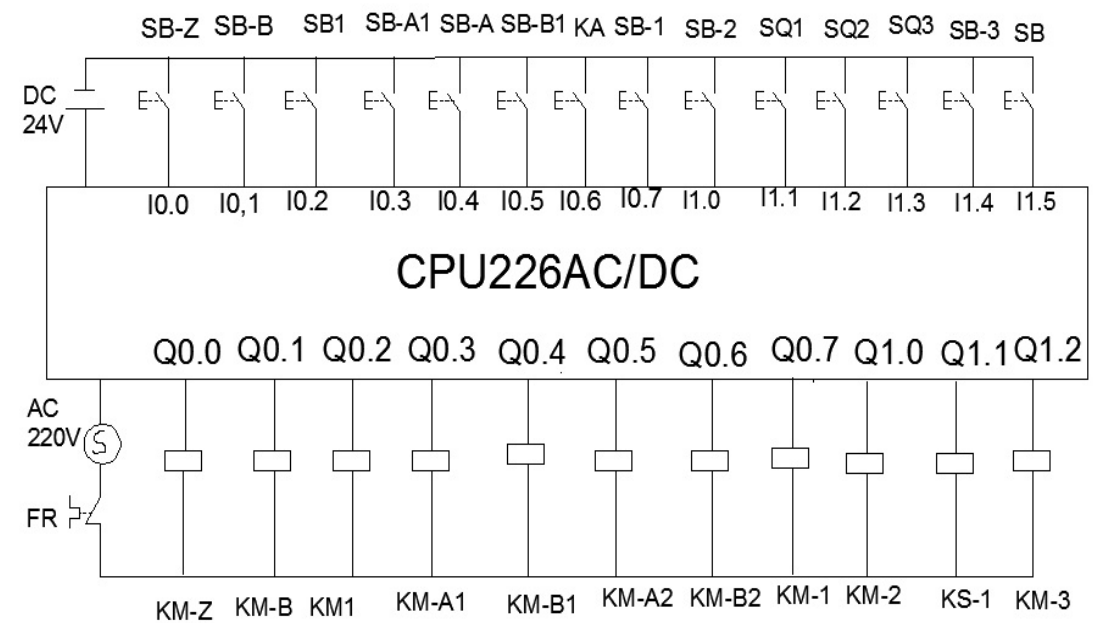

Figure 6: PLC electrical wiring diagram 


\section{Debugging}

With edited PLC programs to make simulation, connected all ladder together, blue means it is running smoothly.

(1) Press the button SB-Z, input terminal I0.0, then the main pump start running;

(2) When the main pump was not working properly, press the button SB-B, input terminal I0.1, then the standby pump start running;
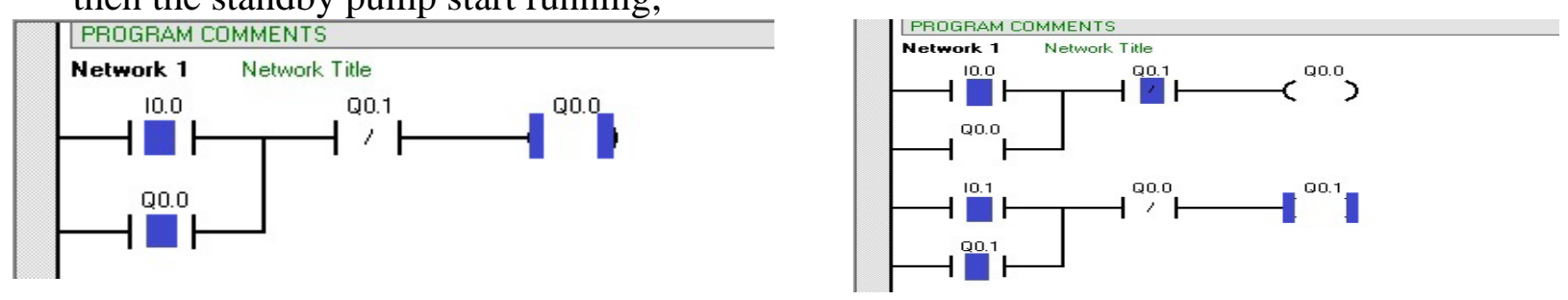

(3) Press the button SB1, input terminal I0.2, the booster pump start running;

(4) Press the button SBA1, input terminal I0.3, dual power supply main supply line;
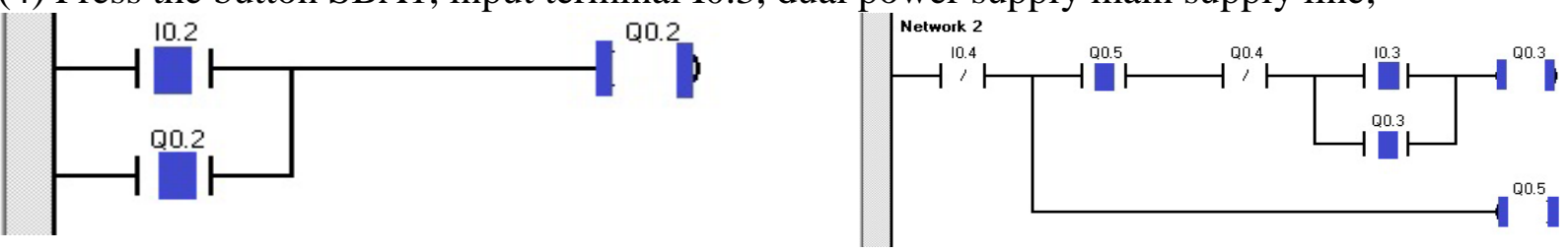

(5) When the dual power main line outage, the standby line is power supply;

(6) Press the button SB1, input terminal I0.7, telescopic rails manual start, press the button SB-2, input terminal I1.0,then the rail retracted;
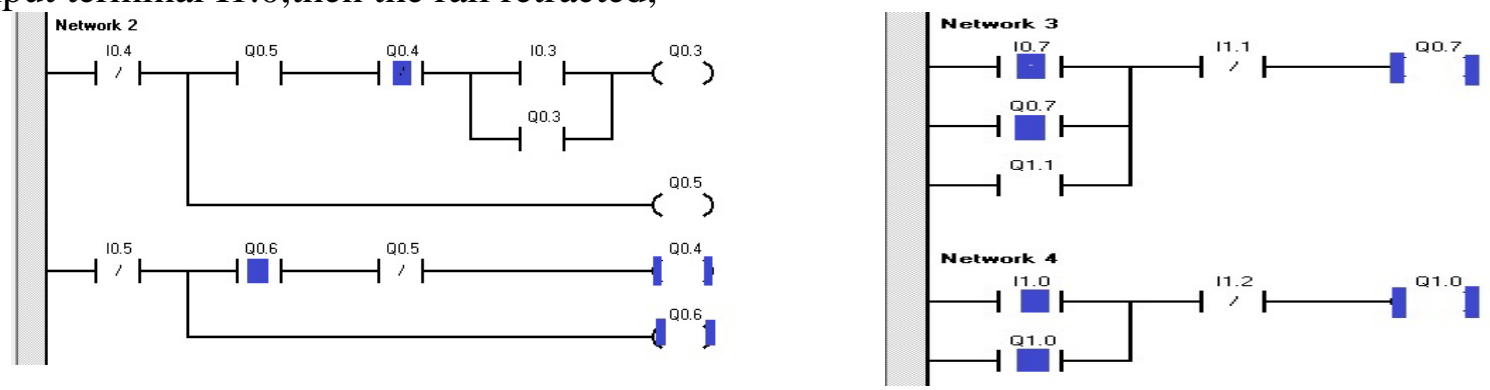

(7) When the guide rail extended and retracted refuge floor, input terminal I1.1 and I1.2.

(8) When fire occurred, the signal relay KA closed, the signal relay is energized, the auxiliary contacts are closed so that the control rail contactor is energized, the rails extend, switch limit to be set at a certain position;
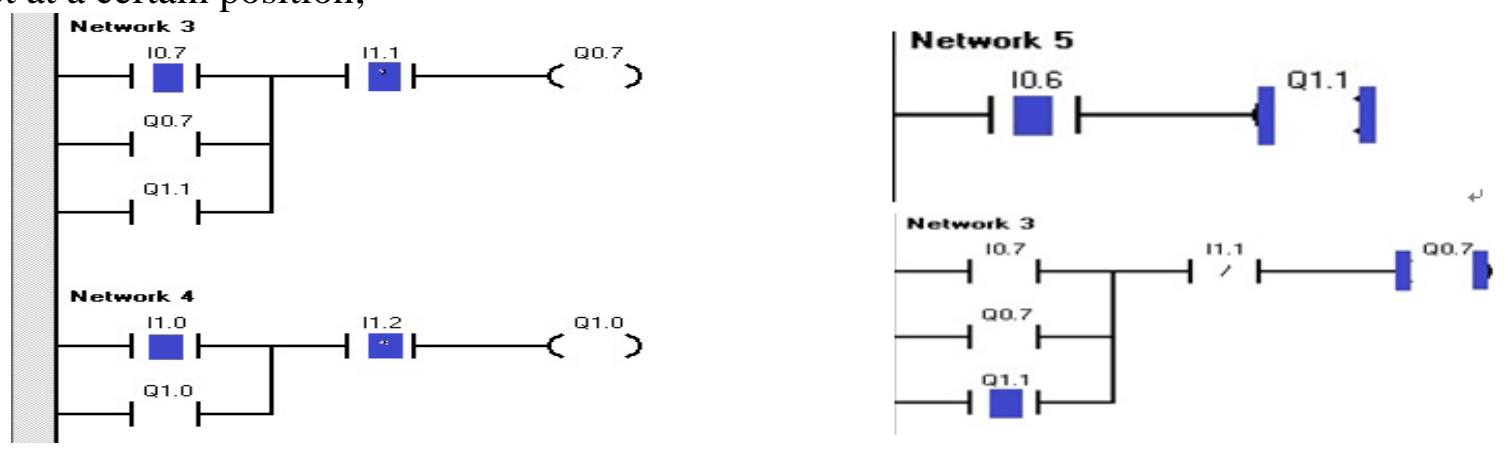

(9) Press the button SB3, input terminal I1.4, manually start the electric motor which control the cylinder then I1.1 and I1.3 interlock, when the rail extended refuge floors, SQ1 off, SQ3 to be closed can also control the rail extends.

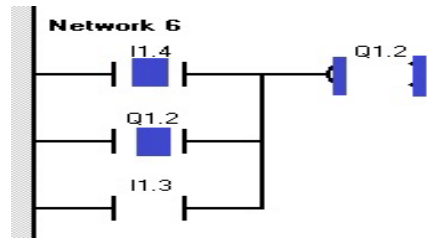




\section{Conclusion}

Embedded retractable fire extinguishing and rescue equipment control system is mainly making use of a remote control system to put out the high-rise building fire, by using the programmable controller to control the entire extinguishing process. The fire control system equipment is simple, high efficiency. Through text and graphics, describing extinguishing process, also executed software simulation, to prove the rationality of this design. High-rise building fire is a major problem in today's society, in recent years, high-rise building fires have caused heavy casualties, but we don't have effective firefighting equipment to quickly and accurately put out the fire, this set of system is to solve this worldwide problem and to provide a solution for firefighting and rescue, making a meaningful contribution to the world high-rise building fire rescue.

\section{Acknowledgement}

This research was financially supported by the Hebei Province Science and Technology Foundation (No.Z2015072, No.15275508) and NCIST Foundation (No. 3142015023).

\section{References}

[1] G. Si, High-rise building fire of China [J]. Fire Science and Technology .2010 (10)

[2] Q. Li, Analysis of high-rise building sprinkler systems and electrical linkage control link [J]. China New Technology and New Products .2014 (11)

[3] M. Zhang, G. S. Wang, Fire alarm and linkage control system [J]. Fire Technology and Products Information. 2004 (11)

[4] Y. H. Li, X. J. Huang, Z. X. Zhang ,Selection and application technology discussion of automatic fire extinguishing system [J]. Fire Science and Technology .2011 (11)

[5] A. M. Zhao, Y. S. Lu, Modern high-rise building fire safety Discussion [J].Police Force Academy. 2007 (04)

[6] Q. Q. Geng. Automatic fire extinguishing system key technology [J].Information Systems Engineering .2015 (09)

[7] X. H. Feng, C. L. Wang, Modern electrical control and PLC application [M] 1st edition. Beijing: National Defense Industry Press, 2013

[8] Practical Electrical Engineering Design Manual [M] 1st edition Shanghai: Shanghai Science and Technology Literature Publishing House .2011 